\title{
Gain-flattened dual-stage L-band EDFA by using pump power distribution
}

\begin{abstract}
An L-band erbium doped fiber amplifier (EDFA) with dual-stage architecture was proposed that gives a considerably flatten wavelength response of less than $3 \mathrm{~dB}$ gain variations. Gain of $25 \mathrm{~dB}$ was achieved throughout the L-band region $(1570 \mathrm{~nm}-1605 \mathrm{~nm})$ and noise figure of less than $4.5 \mathrm{~dB}$ was obtained when the pump power was distributed equally to two different stages with different length of erbium-doped fiber (EDF). Without applying any gain equalizing filters, this architecture able to demonstrate a flat gain spectrum when the input signal power was varied from $-30 \mathrm{dBm}$ to $-15 \mathrm{dBm}$.
\end{abstract}

